\section{QUALITY AND QUANTITY IN SPACE AGE LITERATURE}

\section{Rocket Engines}

By S. L. Bragg. Pp. $158+6$ plates. (London: (George Newnes and Co., Ltd., 1962.) 35s. net.

\section{Ballistic Missile and Space Vehicle Systems} \section{Edited by Prof. Howard S. Seifert and Kenneth} Brown. (Engineering and Physical Science Extension Series, University of California, Los Angeles.) Pp. xii + 526. (New York and London: John Wiley and Sons, Inc., 1961.) 96s.

O the many things with which we have been inflicted since the U.S.S.R. made the first moves into the 'Space Age' in October 1957, one is a proliferation of space literature and most of it is mediocre. Perhaps editors and authors, inspired by the vastness of space, are making desperate efforts to fill the void with words. Fortunately, we occasionally find an author who imposes strict limitations on himself and gives himself a precise objective. It would seem that Bragg is such an author.

With only a fow innocent digressions from his objective, Bragg presents the important processes within a rocket engine in a logical and concise manner. The overall impression is that one is following the thoughts of a man, sufficiently alert to discard trivialities, who is ascertaining what is of basic importance. The result is a pleasant and readable book which. with a few words of caution, can be firmly recommended to students and anyone interested in rockets. Some of the lapses from strict accuracy will be discerned immediately by the knowledgeable reader and later by those who are inspired to delve more deeply into rocket technology, but I myself would like to comment on statements made in sections 4.7 and 5.5. In the former section the relationship brtween propellent density and specific impulse is a sufficiently accurate approximation for the example quoted, but this examplo is scarcely typical of guided missiles. The spectrum of missile designs is so wide that a single typical example cannot be quoted and the relationship between propellent density and specific impulse is more complicated than the author implies. The statement, on p. 91 in the latter section, to the effect that the drop in pressure generated in a combustion chamber by heat addition is not really a loss is both puzzling and incorrect. When heat is added to a gas flowing in a duct, it suffers a fundamental loss in total pressure which cannot be recovered by subsequent cooling. The extent of this fundamental loss is dependent on the degree of acceleration permitted, which in turn is dependent on the geometry of the duct, as Fig. 5.4 indicates.

In marked contrast to Bragg, Seifert and Brown have endeavoured to cover the whole gamut of disciplines and tochnologies necessary to design a launching vehicle and inject a satellite into orbit. If they had succeeded in this task a really remarkable book would have been created; but it would have been of stupendous size. As it is, the book is too large when measured by the authority which it wields. The first chapter, "Systems Engineering", carries tautology to extreme limits. Its fourteen pages may be summarized as "Authority is vested in the systems engineer to ensure concentration, coordination and collaboration". If the two editors had assumed this authority something much better would surely have emerged. What. in fact, has emerged is a series of articles cach of a superficial character, and there is little evidence that the authors have perused their own efforts and still loss that they have collaborated between themselves. I am unable to visualize the reader who will derive much satisfaction from Ballistic Missile and Space Vehicle Systems. It is certainly not the specialist: in propulsion nor structures nor guidance and control. Who is left but some enigma! He may call himself a "Systems Engineer", but he is more likely to be a "Jack of all Trades".

Our language is flexible enough to meet the requirements of modern technology yet we abuse it in an appalling manner. Bragg departs from his grandfather's precepts and meekly accepts "propellant", but worse still, Seifert and Brown have accepted such abominations as "outage" and "fabricability". In both books the word "parameter" is frequently used, but never with its correct meaning. Few of us, who claim to have any scientific training, are endowed with much literary sense. If we humbly acknowledge this we are likely to be more careful and less likely to make mistakes. J. F. P. Dunninc:

\section{REACTOR PHYSICS PRINCIPLES SIMPLY EXPLAINED}

\section{Textbook of Reactor Physics}

An Introduction. By J. F. Hill. Pp. 227. (London: George Allen and Unwin, Ltd., 1961.) 36s. net.

THIS book is a useful addition to the alreadv numerous texts on reactor physics, and will provide casy reading to the many non-specialists who, although working in atomic energy, are not involved in detailed reactor physics calculations. It also provides a stepping-stone between oxisting elementary and advanced works for those wishing to specialize in the subject. In the writing of this book the author has drawn on the valuable experience he gained in teaching reactor physics to engineers and scientist is while principal of the Harwell Reactor School. He has therefore given clear physical pictures, without using involved mathematics, of the complex processes taking place in a nuclear reactor and anticipated the difficulties which come to the mind of the engineers and seientists who have little or no physics background.

The book starts with an excellent summary on basic atomic and nuclear physics followed by a discussion on chain reactions and physics problems of reactor design. A section on binding energy in this chapter, relating to the mass number-binding energy curve, is slightly misleading. These topics are followed by a chapter or neutron behaviour in moderators, including an appendix clearly explaining the laboratory and centre of mass systems, neutron scattering and energy losses in collisions.

Chapter 5 describes reactor parameters and discusses the critical size of a homogeneous reactor, starting with the 4 factor formula and including many useful graphs showing how these main parameters are affected, for oxample, by the ratio of the number of moderator to uranium atoms. This chapter, of necessity, includes sections on the diffusion and slowing down lengths of neutrons, and it would be most useful if in future editions the author could add small appendixes on these topics.

Chapter 6 shows the effect on the reactor parameters of changing from a homogeneous to a heterogeneous system. It also gives numerical examples and 